NASA Technical Memorandum 107579

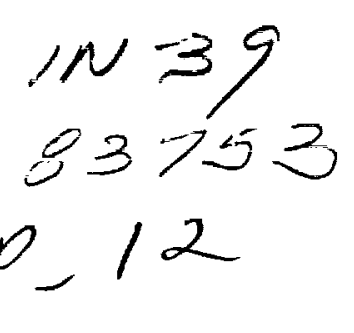

\title{
THE NASA/INDUSTRY DESIGN ANALYSIS \\ METHODS FOR VIBRATIONS (DAMVIBS) \\ PROGRAM - A GOVERNMENT OVERVIEW
}

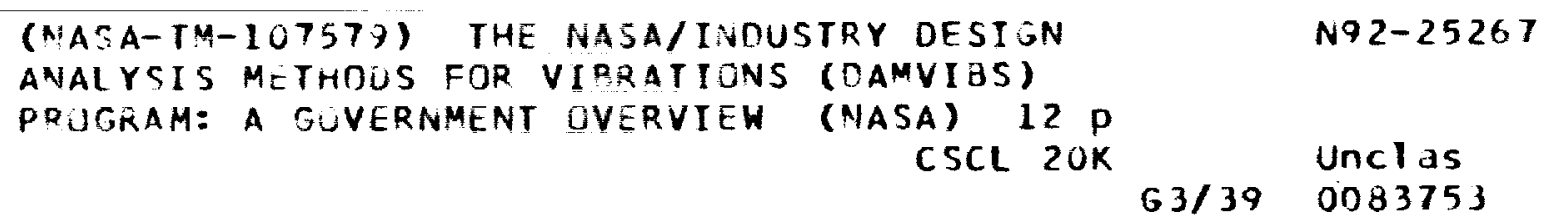

Raymond G. Kvaternik

April 1992

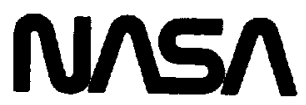

National Aeronautics and

Space Administration

Langley Research Center

Hampton, Virginia 23665-5225 


\title{
The NASA/Industry Design Analysis Methods for Vibrations (DAMVIBS) Program - A Government Overview
}

\author{
Raymond G. Kvaternik \\ NASA Langley Research Center \\ Hampton, Virginia
}

\begin{abstract}
NASA-Langley, under the Design Analysis Methods for Vibrations (DAMVIBS) Program, set out in 1984 to establish the technology base needed by the rotorcraft industry for developing an advanced finite-element-based dynamics design analysis capability for vibrations. Considerable work has been done by the industry participants in the program since that time. Because the DAMVIBS Program is being phased out, a government/industry assessment of the program has been made to identify those accomplishments and contributions which may be ascribed to the program. The purpose of this paper is to provide an overview of the program and its accomplishments and contributions from the perspective of the govemment sponsoring organization.
\end{abstract}

\section{Introduction and Background}

Excessive vibrations have plagued virtually all new rotorcraft developments since the first U. S. helicopter went into production over 40 years ago. Although vibration levels have been reduced considerably in production aircraft during this period of time, vibration problems continue and have occurred even in modern rotorcraft designs. With only a few exceptions, vibration problems have not been identified and addressed until flight test (ref. 1). Solutions at that stage of development are usually add-on fixes which adversely impact cost, schedule, and vehicle performance. The finite-element method of structural analysis is widely used by the helicopter industry to calculate airframe static internal loads and for the usual checks on frequencies. The calculated static loads are used routinely in design for sizing structural members (refs. 2-3). Until recently, however, vibration predictions based on finite-element analyses have not been used much by the industry during design because they were considered unreliable as a basis for making design decisions (refs. 4-6).

* Aerospace Engineer, Structural Dynamics Division, Associate Fellow AIAA, Member AHS
The problems facing analysts charged with predicting helicopter vibrations are formidable (fig. 1). The rotor system generates complex periodic aerodynamic and dynamic loads which are transmitted to the airframe both mechanically through the mounting system and aerodynamically by the rotor wake. The loads mechanically

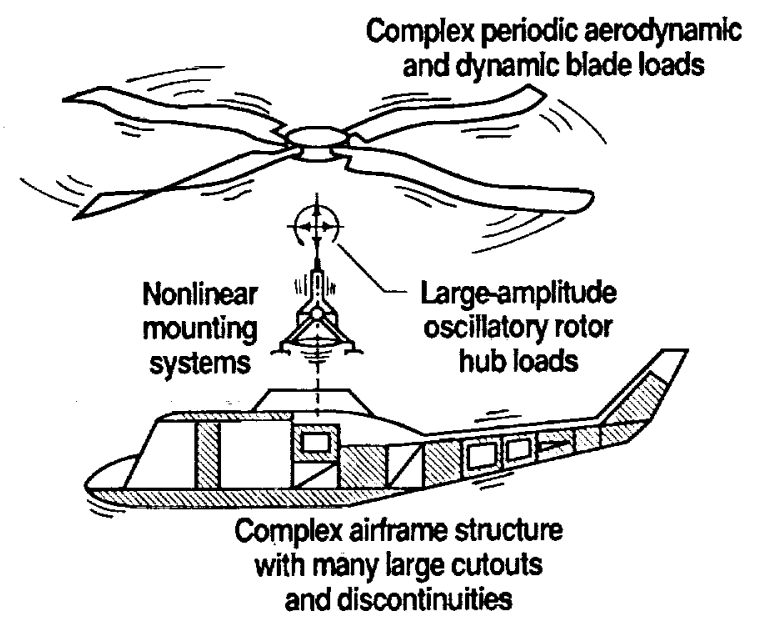

Figure 1.- Challenges confronting analysts in predicting helicopter vibrations.

transmitted are generally the larger and occur primarily at the blade passage frequency, which is equal to the product of the number of blades and the rotor rotational speed. This frequency is in the range 10 to $20 \mathrm{~Hz}$ for current helicopters. The airframe structural dynamics problem is complicated by the fact that helicopter airframes are light-weight, shell-type structures having multiple large cutouts and supporting several rather heavy components. Even with the advanced analysis capability offered by finite-element methods, until recently airframe structural designers have achieved only limited success in designing airframes which exhibit adequate vibratory response characteristics. A major deficiency has been an incomplete understanding of the modeling requirements for vibration analysis of complex helicopter structures. Thus, airframe dynamic analyses have not been a very effective tool in the design process. This situation has resulted in an excessive reliance on vibration control devices. 
The need for more effective use of airframe finiteelement models during the design process in efforts to reduce vibrations prompted industry advisory groups during the late 1970s to begin calling for NASA to work with the industry on improving the predictive capability of airframe finite-element vibration models. At about the same time, NASA's Office of Aeronautics and Space Technology formed a special task force to review rotorcraft technology needs and to prepare an appropriate agency-wide rotorcraft research program aimed at advancing technology readiness over a broad front. The draft plan cited vibrations as one of the key areas NASA intended to work as part of a proposed new 10-year rotorcraft research program. As lead center for structures research, Langley Research Center was asked to define a research activity aimed at addressing the industry's needs with respect to improving the dynamics predictive capability of finite-element models. The proposed task, which appeared in the final report of the task force (ref. 7), called for an application of finiteelement vibration modeling in a workshop environment to assess and document industry modeling techniques and ground vibration test procedures. In 1980, Boeing Helicopters won a contract to conduct the subject study on the $\mathrm{CH}-47 \mathrm{D}$ helicopter. This study was completed in 1983.

During the course of the studies conducted on the CH-47D helicopter, it became clear that what was needed to establish the required finite-element modeling technology base was an industry-wide program in which all the companies conduct modeling, testing and correlation activities, all in a workshop environment conducive to technology transfer. As a culmination of considerable planning by NASA and the industry during the course of the $\mathrm{CH}-47 \mathrm{D}$ study, all in close coordination with the U. S. Army, a multi-year, industry-wide program directed at the long-term needs of the industry with respect to predicting and controlling vibrations, with primary attention to issues related to finite-element modeling, was defined. Because the objective of the expanded program was to establish the technology base needed by the industry for developing an advanced finite-element-based dynamics design analysis capability for vibrations, the new program came to be called DAMVIBS (Design Analysis Methods for VIBrationS).

The DAMVIBS Program was initiated in 1984 with the award of task contracts to the four major helicopter airframe manufacturers (Bell Helicopter Textron, Boeing Helicopters, McDonnell Douglas Helicopter Company, and Sikorsky Aircraft Division of United Technologies Corporation). Considerable work has been conducted by the industry participants in the program since that time. Five government/industry workshops have been held to review and discuss results and experiences of those activities. Because the DAMVIBS Program is being phased out, the last meeting included a special session devoted to an assessment of the program to identify those accomplishments and contributions which may be attributed to the program.

The purpose of this paper is to provide an overview of the DAMVIBS Program and its accomplishments and contributions, including the initial finite-element modeling study which was conducted on the $\mathrm{CH}-47 \mathrm{D}$, from the perspective of the government sponsoring organization. Emphasis throughout is on contractor results. A more complete summary of the DAMVIBS Program, which also includes contributions to the program resulting from in-house research activities as well as funded university work, may be found in reference 8 .

\section{Initial Finite-Element Modeling Program (The CH•47D Study)}

\section{Objective/Scope/Approach}

The vibrations work proposed by the NASA rotorcraft task force (ref. 7) was to involve participation by NASA and the industry in a workshop environment to assess and document industry modeling techniques and ground vibration test procedures. All the work was to be done on a production aircraft. As a result of a competitive procurement, a contract was awarded to Boeing Helicopters in 1980 to conduct such a study on the CH-47D tandem-rotor helicopter. The contract required that plans for the modeling, testing and correlation be formulated and submitted to both government and industry representatives for review prior to undertaking the actual modeling and testing. In particular, modeling guides were required as part of the modeling plan for each unique type of structural member in the CH-47D airframe. Boeing was also required to make a study of current and future uses of finite-element models and to keep meticulous records on the man-hours required to form the vibration model. The work was deliberately slow paced to allow for the necessary extensive government/industry interactions and technical exchanges. The studies conducted on the CH-47D have been extensively documented in a series of NASA Contractor Reports (refs. 9-13).

\section{Illustrative Results and Key Findings}

The finite-element model developed as part of the study is shown in figure 2 . An extensive ground vibration test was also conducted on the airframe (fig. 3). The airframe was excited by forces vertically, longitudinally, and laterally and by moments in pitch and roll at both the forward and aft hubs over the frequency range from 5 to $35 \mathrm{~Hz}$. While the correlations obtained between measured and calculated responses (see, for example, fig. 4) are considerably improved over previous work, particularly at the lower frequencies, the predicted responses were found to exhibit acceptable agreement with test only up to about $15-20 \mathrm{~Hz}$. 


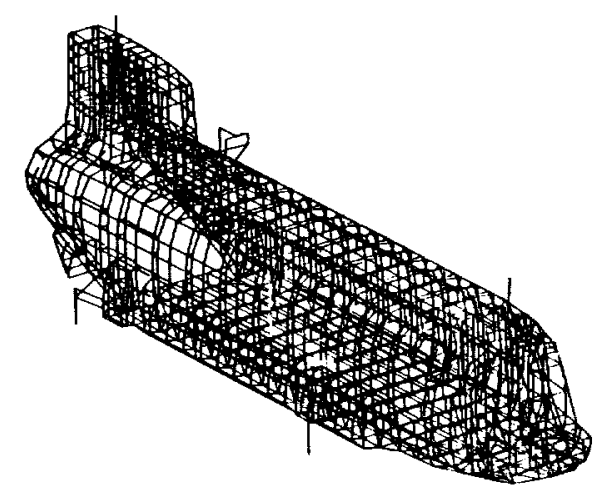

Figure 2.- CH-47D finite-element model.

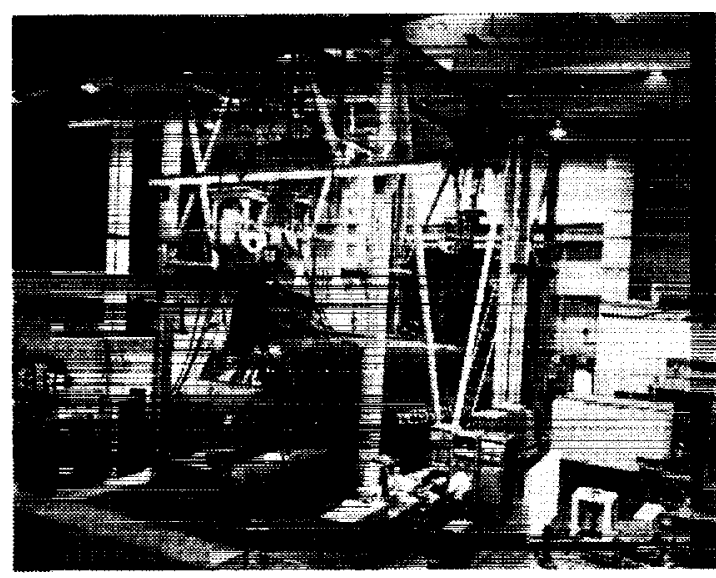

Figure 3.- Ground vibration test of $\mathrm{CH}-47 \mathrm{D}$.

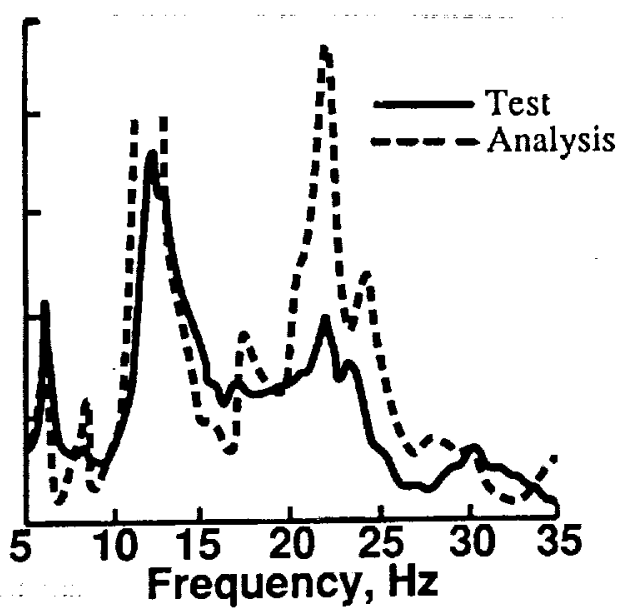

Figure 4.- Comparison of measured and calculated responses of $\mathrm{CH}-47 \mathrm{D}$ for lateral excitation at forward hub.
The CH-47D studies identified several modeling considerations which have the potential for improving the correlation if accounted for in the finite-element analysis. For example, the effects of support systems and excitation systems on airframe elastic responses measured in a ground vibration test are typically assumed to be negligible and finite-element models are usually formed for the airframe in a free-free (unrestrained) configuration. A method for including these effects in the finite-element dynamic analysis while taking into account the prestiffening effects due to gravity was devised by a NASA team and applied to the CH-47D by Boeing. While only minor effects were noted for the $\mathrm{CH}-47 \mathrm{D}$, the effects may not be negligible for other configurations, particularly at the higher frequencies. Two issues related to the modeling of stringers were identified and shown to be important. The first concerns the treatment of stringers which are discontinuous across manufacturing splices. The upper portion of such joints is in compression under $1-\mathrm{g}$ loading, resulting in effective axial continuity of unconnected stringers. The second issue concerns stringer shear area. Although airframes usually contain many stringers, the cross-sectional areas of the stringers are not considered as contributing to the total effective shear area of a cross section because of the usual assumption which is made that the skin carries all the shear load. Analytical studies made using the $\mathrm{CH}-47 \mathrm{D}$ finite-element model showed that the shear load carried by the stringers may not be negligible as previously assumed.

Several other findings emerged from the $\mathrm{CH}-47 \mathrm{D}$ studies. A finite-element model was judged to be an essential ingredient of any design effort aimed at developing a helicopter with low inherent vibrations. Modeling guides prepared during the planning phase enabled proper planning, scheduling, and control of the modeling effort. Up-front planning of the static and dynamic finite-element models before modeling begins was shown to be the key to forming a single model suitable for computing both static internal loads and vibrations and to improving the quality of the models. It was clearly established that a finite-element model suitable for the computation of both static internal loads and vibrations can be formed early enough in a new helicopter development program to actually influence the airframe design. The cost of such a model was shown to be about 5 percent of the total airframe design effort. Because 4 percent is typically expended for the static model, the vibration model is only another one percent. While the correlations which have been obtained are much improved over previous work, particularly at the lower frequencies, the correlation needs to be improved at the higher frequencies. Significantly improved correlation appears possible by including in the models effects historically considered to be unimportant dynamically, such as the shear load carrying capability of stringers and the dynamics of airframe ground vibration test suspension systems. 


\section{DAMVIBS - The Expanded Finite-Element Modeling Program}

\section{Formative Influences}

During the course of the $\mathrm{CH}-47 \mathrm{D}$ study it became clear that the key to improving modeling technology and engendering in the industry the needed confidence to use finite-element models for vibrations design work was more hands-on experience along the lines of the $\mathrm{CH}-47 \mathrm{D}$ study. Also identified as being essential was a workshop environment which fostered the open discussion of airframe finite-element modeling issues, techniques, and experiences. The $\mathrm{CH}-47 \mathrm{D}$ experience, the continuing validity of the NASA Task Force Report, and the need of the industry for an advanced vibrations design analysis capability were the catalysts for the Langley Rescarch Center to begin formulating an expanded finite-element modeling program involving the four primary helicopter airframe manufacturers (Bell Helicopter Textron, Boeing Helicopters, McDonnell Douglas Helicopter Company, and Sikorsky Aircraft Division of United Technologies Corporation). As a culmination of considerable planning and coordination work by NASA and the industry, a multi-year prō $\overline{g r a m}$ was defined, approved by NASA, and subsequently implemented in 1984 with the award of task contracts to the aforementioned companies. As mentioned earlier, because the emphasis of the program was to be on improving finite-element analyses for supporting vibrations design work, the program came to be called DAMVIBS (Design Analysis Methods for VIBrationS).

\section{Objective/Scope/Approach}

The overall objective set down for the DAMVIBS Program was the establishment in the U. S. helicopter industry of an advanced capability to utilize airframe finite-element models in analysis of rotorcraft vibrations as part of the reguTar airframe structural design process. The intent was to achieve a capability to make useful analytical predictions of helicopter vibration levels during design, and to design on the basis of such predictions with confidence.

The scope of the DAMVIBS Program, as laid out in 1984 when it was made the focus of a new rotorcraft structural dynamics program which was initiated at Langley at that time, is shown in figure 5. Four technology areas were to be worked under the DAMVIBS Program: (1) Airframe Finite-Element Modeling; (2) Difficult Components Studies; (3) Coupled Rotor-Airframe Vibrations; and (4) Airframe Structural Optimization. Primary emphasis was to be on the first two elements of the program, which were intended to be mainly an industry effort focusing on industrial modeling techniques. Under the last two elements of the program, the finite-element models formed by the industry were to be used by government, industry and academia as the basis for the development, application, and evaluation of advanced analytical and computational techniques related to coupled rotorairframe vibrations and to airframe structural optimization under vibration constraints.

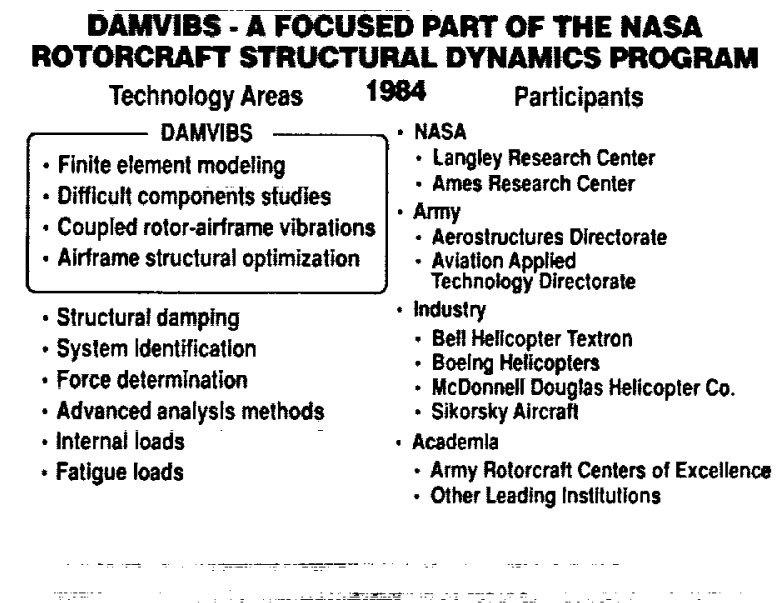

Figure 5.- DAMVIBS positioned as focus of Langley rotorcraft structural dynamics program.

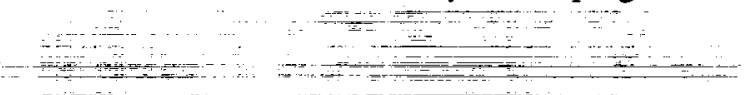

To maintain the necessary scientific observation and control, emphasis throughout these activities was to be on advance planning, documentation of methods and procedures, and thorough discussion of results and experiences, all in a workshop environment to allow maximum technology transfer between companies.

\section{Illustrative Results and Key Findings}

Airframe Finite-Element Modeling.- The purpose of this program element was to develop stateof-the-art finite-element models for internal loads analysis and vibrations analysis of airframes of both metal and composite construction. The activities included modeling, testing, and test/analysis correlation. The main technical products of this series of activities were to be: (1) Basic modeling guides; (2) Validated models of significant airframes; and (3) Identification of needed research tasks aimed at strengthening finiteelement modeling. Each contracted activity was to produce a well-documented model of the subject aircraft that could be used and studied by groups other than the developers. Ground vibration tests were to be conducted as required for correlation with analytical results. Whenever practical, however, existing experimental results were to be used to the fullest extent possible. 
Industry teams have formed finite-element models (fig. 6), conducted ground vibration tests (fig. 7), and made extensive test/analysis comparisons (fig. 8) of both metal and composite airframes. The results of these studies are described fully in references 14-22. In a related activity, a company-developed method for identifying modeling errors which can arise while forming a finite-element model (ref. 23) was publicized and subsequently adopted by the other companies.

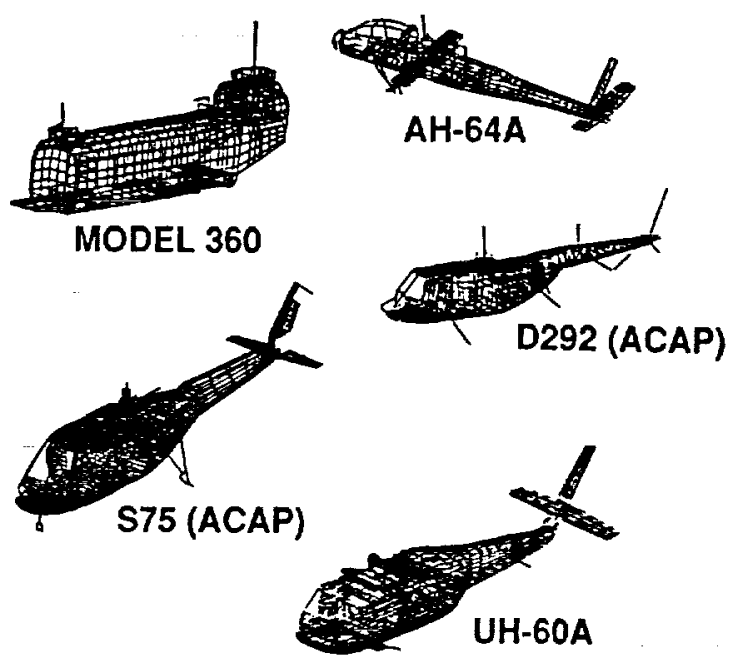

Figure 6.- Finite-element models formed.
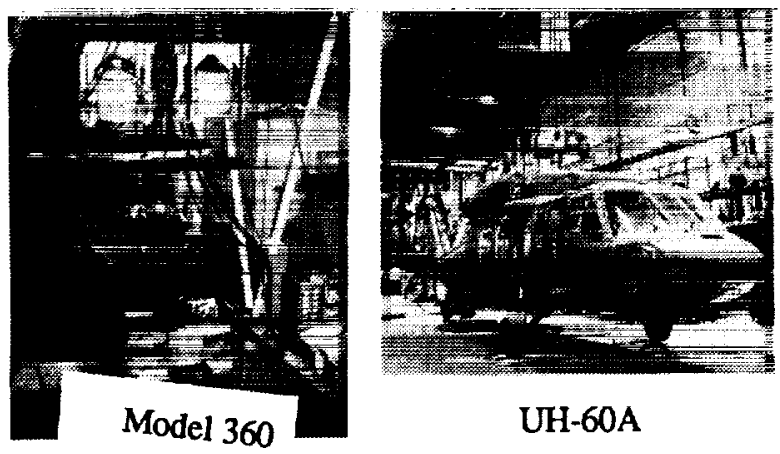

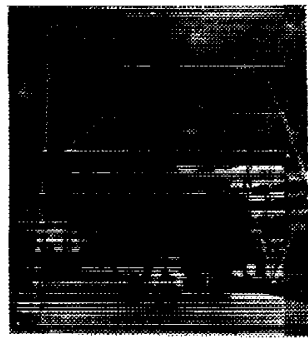

AH-64A

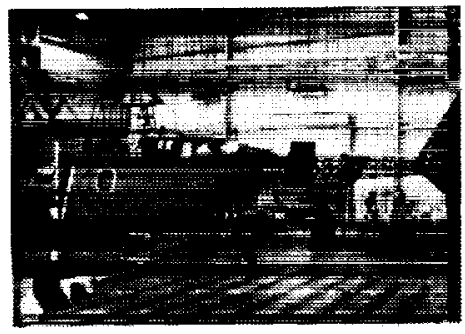

D292 (ACAP)

Figure 7.- Ground vibration tests conducted.
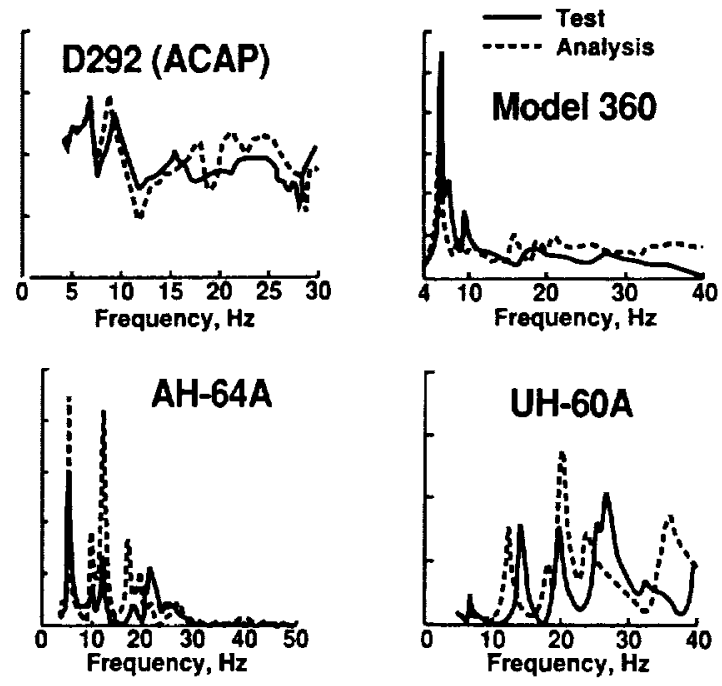

Figure 8.- Typical test/analysis comparisons of airframe frequency response amplitudes.

The Airframe Finite-Element Modeling studies have reaffirmed that up-front planning before modeling begins reduces the effort needed to form unified static and dynamic models and improves the quality of the initial models. To form such models, the statics, dynamics, and weights groups need to work closely together to adopt modeling procedures which are compatible with both static and dynamic modeling requirements. These studies have confirmed the finding of the $\mathrm{CH}-47 \mathrm{D}$ study that a finite-element vibration model can be formed early enough to influence the design of a new airframe and that the cost of such a model is quite nominal if the static model has to be formed. Structural modeling techniques for both metal and composite airframes are relatively uniform within the industry. Modeling techniques for metal and composite airframes are similar except for the determination of element material properties. These properties are significantly more difficult to generate for composite airframes because the composition of the laminate for each structural element must be determined from design drawings, analyzed for its resultant stiffness, and the result transferred to the finite-element model. Test/analysis comparisons for all the airframes studied indicate that agreement is good up through about $10 \mathrm{~Hz}$, only partially satisfactory from about $10-20 \mathrm{~Hz}$, and generally unsatisfactory above about $20 \mathrm{~Hz}$. The dynamics of composite airframes are more difficult to predict than for metal airframes. Ground vibration tests indicate that support system effects can be important and may need to be routinely included as part of the airframe finite-element model. Damping levels were found to be essentially the same in both metal and composite airframes. Better definition and representation of damping is needed in finite-element analyses. 


\section{CRIGINAL PAGE \\ BLACK AND WHITE PHOTOGRAPH}

Difficult Components Studies.- In the basic modeling studies conducted under the DAMVIBS Program only the primary (major load carrying) structure was represented fully (stiffness and mass) when forming the finite-element models. However, as depicted in figure 9 for the AH-1G, there are many components and secondary structure which are represented in the model only as lumped masses. While this is consistent with customary modeling practice, this may be a major contributing factor to the poor agreement which has been noted between test and analysis at the higher frequencies of interest. The aim of the difficult components studies is to identify the effects of such modeling assumptions and to develop improved modeling guides for components which are determined to require better representation for improved correlation. Difficult components studies have been conducted on the all-metal AH-1G and the all-composite D292 and are presently underway on the all-composite S75.

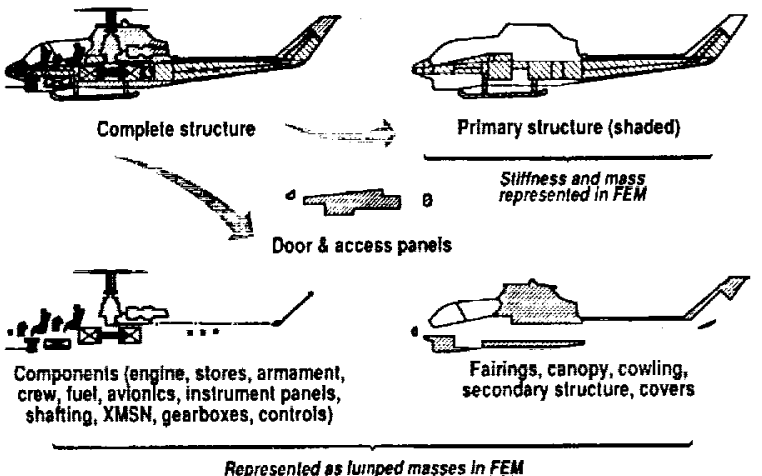

Figure 9.- Usual treatment of airframe structure in finite element modeling.

The first difficult components study was conducted by Bell on the AH-1G helicopter, a detailed account of which is given in reference 24 . The airframe in its fullup ground vibration test configuration is shown in figure 10a. Components were then progressively removed from the aircraft - main rotor pylon/transmission assembly, secondary structure panels, tail rotor drive shaft, skid landing gear, engine, and fuel - to arrive at the configuration shown in figure $10 \mathrm{~b}$. The canopy glass, various black boxes, and the stub wings were then removed in the last step of the strip down. At each stage, a ground vibration test and an analysis based on an existing finite-element model that was modified to reflect the specific configuration tested were performed and the results compared. Comparisons of measured and predicted changes in response were then used to identify components which were causing prediction difficulties and which therefore required better modeling treatment. For example, the

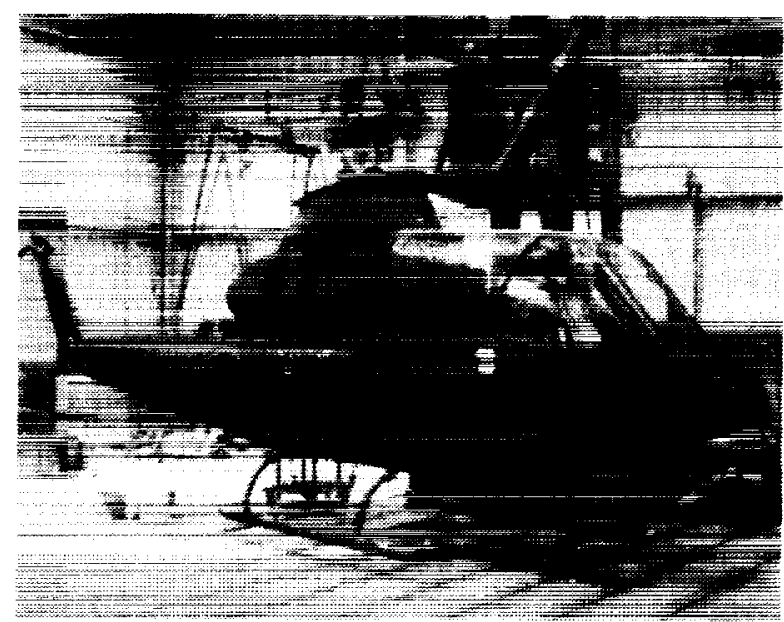

(a) Complete airframe

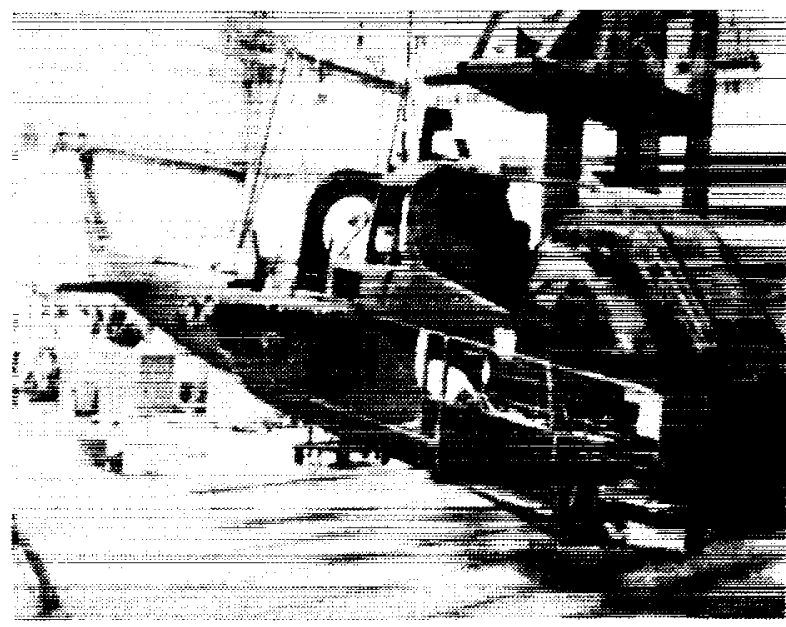

(b) Stripped-down airframe

Figure 10.- Difficult components study of AH-1G.

secondary structure panels under the canopy from just aft of the nose to just forward of the wings and the canopy glass were found to have a considerable effect on the response at the higher frequencies.

Based on the results of such comparisons, the finiteelement model was updated to include some of the effects which were found to be important. The improved model was then used to reanalyze each of the configurations tested. The improvement in the predicted frequencies is indicated in figure 11. In that figure the predicted natural frequencies are plotted versus the measured frequencies for all the major configurations tested using both the initial and updated finite-element models. In each case, perfect agreement is along the solid line. It is seen that the natural frequencies calculated using the updated model are generally within 5 percent of test values, compared to 20 percent using the initial model. 
INITIAL
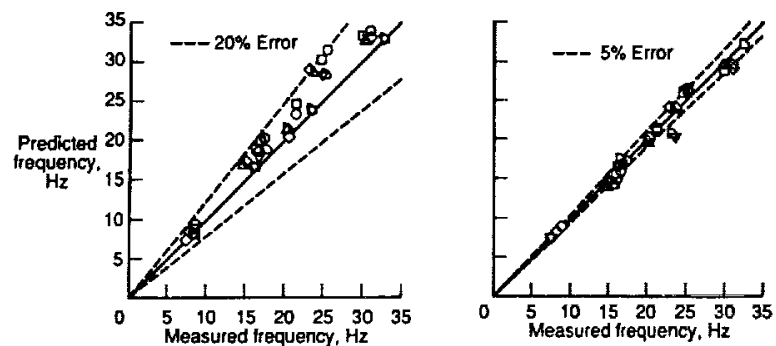

Figure 11.- AH-1G natural frequency comparisons using initial and improved models.

A difficult components study was recently completed on the D292 helicopter (ref. 25). The ground vibration test was conducted by the Army's Aviation Applied Technology Directorate at Fort Eustis as part of the subject investigation. Natural frequencies calculated using an updated model were within 10 percent of test values, compared to 20 percent using the initial model. Ground vibration tests are underway by the Army on the S75 helicopter as part of the difficult components investigation which is being conducted on that helicopter airframe. The finite-element model to be used by Sikorsky in the analytical portion of that investigation was shown in figure 6. This is the last contracted task to be performed under the DAMVIBS Program.

The Difficult Components Studies have shed new light on the importance of many airframe components on vibratory response at the higher frequencies of interest. The stiffness of tight secondary structure panels and sealed canopy glass must be modeled. A lumpedmass representation is generally sufficient for such components as the tail rotor drive shaft, engines, fuel, and soft-mounted black boxes. Elastic-line representations appear to be adequate for such components as the main rotor pylon/transmission, skid landing gear, and wings, but wholly inadequate for beam-like tail booms at the higher frequencies. The effects of nonproportional structural damping are important at the higher frequencies of vibration. Nonlinear effects of elastomeric mounts and "thrust stiffening" are important at low frequencies. Considerably improved correlation is possible if secondary effects which have typically been regarded as unimportant dynamically are taken into account when forming the finite-element model. This means that finite-element models for vibration analyses need to be substantially more detailed than the usual static model, contrary to what was previously thought.

Coupled Rotor-Airframe Vibrations.- The object of this program element is to evaluate and improve existing comprehensive methods for computing coupled rotor-airframe vibrations and to develop new computational procedures which are better suited to the repetitive analyses which are required in airframe vibrations design work. Emphasis throughout was to be on the airframe and its coupling with the rotor to compute vibrations of the coupled system. The task did not include the improvement of rotor mathematical models for vibration predictions.

In what was the first comparative evaluation of industry codes for comprehensive analysis of coupled rotor-airframe vibrations, teams from each of the companies have applied different analysis methods to calculate the vibrations of the AH-1G helicopter in steady level flight and compared the results with existing flight vibration data (ref. 26). Figure 12 shows a representative comparison of the $2 / \mathrm{rev}$ (twice per rotor revolution) vertical and lateral vibrations predicted by the companies with vibrations measured in flight (refs. 27-30). (Recall that $2 / \mathrm{rev}$ is the primary main rotor excitation frequency for the two-bladed AH-1G.) It is seen that the predicted $2 / \mathrm{rev}$ vibrations are not in good agreement with measured values. This study showed that industry codes for performing comprehensive vibration analysis of coupled rotor-airframe systems are not yet good enough to be relied on during design. Some ancillary studies conducted as part of this investigation indicated that the impingement of the main rotor wake on the vertical tail contributes to the lateral vibrations. This suggests that both mechanical and aerodynamic load paths into the airframe may be equally important and may need to be included in the computation of coupled rotor-airframe vibrations. The companies have been working to improve their comprehensive coupled rotor-airframe analysis codes since the completion of this study and it is expected that a much-improved capability to predict system vibrations will emerge.

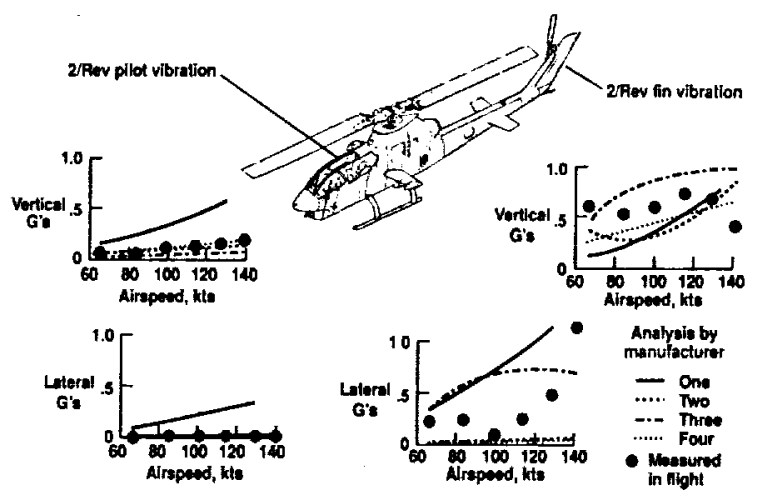

Figure 12.- Industry comparisons of measured and predicted $2 / \mathrm{rev}$ vibrations of $\mathrm{AH}-1 \mathrm{G}$ helicopter.

While the final analytical verification of a design for vibrations will require the use of a comprehensive system analysis which is based on a complex rotor mathematical model, it appears that useful predictions of airframe vibrations can be made during design using simpler models. To investigate this possibility, a 
cooperative study was recently undertaken by NASALangley and the U. S. Military Academy which is aimed at establishing the minimum level of structural and aerodynamic sophistication required in rotor mathematical models for use in coupled rotor-airframe vibration analyses which are intended to support airframe dynamics design work.

Airframe Structural Optimization.- The use of traditional rotor and airframe design techniques to limit inherent vibrations is receiving renewed attention by the industry. It is recognized that structural optimization techniques, if properly brought to bear by the designer, could go a long way toward achieving a low-vibration helicopter. With this in mind, design optimization codes combining finite-element structural analyses with nonlinear programming (NLP) algorithms are in various stages of development in both government and industry. While the DAMVIBS Program contained a technology area called Airframe Structural Optimization, no optimization tasks were ever issued under the contracts. However, under company sponsorship, Bell Helicopter Textron conducted some limited studies related to the use of optimization techniques to improve correlation between measured and computed natural frequencies during the AH-1G difficult components study. It should be remarked that all of the industry participants in the DAMVIBS Program are now moving forward in this area under company sponsorship.

An in-house study has been underway at Langley to investigate the use of formal, NLP-based, numerical optimization techniques for airframe vibrations design work. These studies, which have made extensive use of existing finite-element models of the AH-1G, have shown that structural optimization techniques have considerable potential for playing a major role in airframe vibrations design work, but only if the design models which are required in optimization algorithms adequately reflect the nuances of airframe design.

\section{Assessment of Program}

Five govemment/industry workshops have been held at Langley Research Center during the course of the DAMVIBS Program to review and discuss completed work. Because the DAMVIBS Program is being phased out, the last workshop included a session devoted to an assessment of the program. The assessment, which was made by NASA-Langley and the four industry participants in the program, indicated that considerable progress has been made toward the overall objective of building a design-for-vibrations capability in the U. S. helicopter industry. The DAMVIBS Program was cited for resulting in notable technical achievements and leading to changes in industrial design practice, all of which have significantly advanced the industry's capability to use and rely on airframe finite-element models in analy- sis of vibrations during design. The assessment also identified several key continuing and new structural dynamics challenges which must be met if the industry is to achieve the goal of a helicopter with a "jet smooth" ride.

\section{Major Accomplishments and Contributions}

The major accomplishments and contributions include the following:

(1) Developed industry-wide standards for basic modeling of metal and composite airframes.

(2) Improved industrial finite-element modeling techniques for analysis of airframe vibrations.

(3) Resulted in changes/improvements in industrial design practice for vibrations.

(4) Reversed industry management perception of the utility of finite-element models for vibration predictions. For the first time, such models are being relied on for airfame vibrations design work.

(5) Identified critical structural contributors to airframe vibratory response which require better finite-element modeling.

(6) Showed that considerably improved correlation can be obtained if modeling details which have been historically regarded as of secondary importance are taken into account.

(7) Provided a unique leadership role and focal point for rotorcraft structural dynamics research in govemment, industry, and academia.

(8) Provided the basis for the industry to move forward aggressively on its own to further enhance its capabilities in the subject areas.

\section{Key Continuing/New Challenges}

The key continuing and new structural dynamics challenges which were identified are:

(1) Extend the predictive capability of finite-element models up through the $25-30 \mathrm{~Hz}$ frequency range.

(2) Devise methods for improving models at the finite element level using ground vibration test data.

(3) Develop analytical techniques which more realistically account for structural damping for use in airframe vibrations design work.

(4) Improve the predictive capability of current comprehensive codes for analysis of coupled rotor-airframe vibrations. 
(5) Develop simplified rotor mathematical models which are suited for the repetitive analyses required in airframe vibrations design work.

(6) Define the role of structural optimization in the airframe design process and develop computational procedures tailored for vibrations design work.

(7) Develop new/improved methods for actively and passively controlling airframe structural response.

\section{Concluding Remarks}

In 1984, NASA-Langley, under the Design Analysis Methods for Vibrations (DAMVIBS) Program, set out to establish the technology base needed by the rotorcraft industry for developing an advanced finite-element-based dynamics design analysis capability for vibrations. Considerable work has been done by the industry participants in the program since that time and the program is now being phased out. A recent government/industry assessment of the program has indicated that the DAMVIBS Program has provided the leadership role and focal point for the type of structural dynamics research which was needed by the industry. The program has resulted in notable technical achievements and changes in industrial design practice, all of which have significantly advanced the industry's capability to use and rely on airframe finite-element models in analysis of vibrations during design. Building on the experience of the DAMVIBS Program, each of the industry participants is moving forward aggressively under company sponsorship to further enhance their prowess in the subject areas. As a result, it is expected that the industry will emerge with a substantially-improved finite-elementbased dynamics design analysis capability, which should go a long way towards meeting the dynamics design challenges of the next generation of rotorcraft.

\section{Acknowledgements}

John F. Ward was Manager of Rotorcraft Technology at NASA Headquarters during the definition of the DAMVIBS Program and provided the initial support and encouragement to get the program started. William C. Walton, Jr. and Eugene C. Naumann led in the definition, implementation, and management of the activity which resulted in the CH-47D study. Mr. Walton later led in the definition and implementation of the DAMVIBS Program and prepared coworkers to manage the program in anticipation of his retirement in June 1984. John H. Cline has served as the Technical Representative of the Contracting Officer for the four DAMVIBS task contracts since 1984. Robert J. Huston was Manager of Rotorcraft Research and Technology at Langley during the formative phase of the program and provided advocacy and support when it was needed most. James D. Cronkhite (Bell), Richard
Gabel (Boeing), Mostafa Toossi (McDonnell Douglas), and William J. Twomey (Sikorsky) were the project engineers who headed up the respective industry teams.

\section{References}

1. Schrage, D. P.; and Peskar, R. E.: Helicopter Vibration Requirements. Presented at the 33rd Annual Forum of the American Helicopter Society, Washington, D.C., May 1977.

2. Gallian, D. A.; and Wilson, H. E.: The Integration of NASTRAN into Helicopter Airframe Design/Analysis. 29th Annual Forum of the American Helicopter Society, Washington, D.C., May 1973.

3. Rich, M. J.: Finite Element Analysis of Helicopter Structures. Symposium on Research in Computerized Structural Analysis and Synthesis. NASA CP-2059, 1978, pp. 51-61.

4. Application of Dynamics Technology to Helicopter Design. Panel 3: Integrating Dynamic Analysis and Helicopter Design. Proceedings of the AHS/NASA Ames Specialists' Meeting on Rotorcraft Dynamics, NASA SP-352, February 1974, pp. 327-338.

5. Dean, M. W.: Correlation of an Extended CH-53 Helicopter NASTRAN Model with Full-Scale Aircraft Shake Test Data. NASA CR 145012, 1976.

6. Gaffey, T. M.: Status of Rotorcraft Dynamics Technology. Keynote Address, 39th Annual Forum of the American Helicopter Society, St. Louis, MO, May 9-11, 1983.

7. Advanced Rotorcraft Technology Task Force Report. Office of Aeronautics and Space Technology, NASA, Oct. 15, 1978.

8. Kvatemik, R. G.: The NASA/Industry Design Analysis Methods for Vibrations (DAMVIBS) Program - Accomplishments and Contributions. Presented at the AHS National Technical Specialists' Meeting on Rotorcraft Structures, Williamsburg, VA, October 29-31, 1991.

9. Gabel, R.; Ricks, R.; and Magiso, H: Planning, Creating, and Documenting a NASTRAN Finite Element Vibrations Model of a Modern Helicopter, Planning Report. NASA CR165722, April 1981.

10. Gabel, R.; Kesack, W. J.; and Reed, D. A.: Planning, Creating, and Documenting a NASTRAN Finite Element Vibrations Model of 
a Modem Helicopter, Modeling Documentation Report. NASA CR-166077, March 1983.

11. Gabel, R.; and Reed, D. A.: Planning, Creating, and Documenting a NASTRAN Finite Element Vibrations Model of a Modern Helicopter, Test Requirements Report. NASA CR-165855, April 1982.

12. Gabel, R.; Reed, D. A.; and Ricks, R.: Planning, Creating, and Documenting a NASTRAN Finite Element Vibrations Model of a Modern Helicopter, Ground Shake Test Results and Correlation Report. NASA CR166107, May 1983.

13. Gabel, R.; Kesack, W. J.; Reed, D. A.; and Ricks, R.: Planning, Creating, and Documenting a NASTRAN Finite Element Vibrations Model of a Modern Helicopter, Summary Report. NASA CR-172229, October 1983.

14. Christ, R.; Ferg, D.; Kilroy, K.; Toossi, M.; and Weisenburger, R.: Plan, Formulate and Discuss a NASTRAN Finite Element Model of the AH-64A Helicopter Airframe. NASA CR187446, October 1990.

15. Ferg, D.; Foote, L.; Korkosz, G.; Straub, F.; Toossi, M.; and Weisenburger, R.: Plan, Execute, and Discuss Vibration Measurements and Correlations to Evaluate a NASTRAN Finite Element Model of the AH-64A Helicopter Airframe. NASA CR-181973, January 1990.

16. Dinyovszky, P.; and Twomey, W. J.: Plan, Formulate, and Discuss a NASTRAN Finite Element Model of the UH-60A Helicopter Airframe. NASA CR-181975, February 1990.

17. Howland, G. R.; Dumo, J. A.; and Twomey, W. J.: Ground Shake Test of the UH-60A Helicopter Airframe and Comparison with NASTRAN Finite Element Model Predictions. NASA CR181993, March 1990.

18. Dompka, R. V.; Sciascia, M. C.; Lindsay, D. R.; and Chung, Y. T.: Plan, Formulate, and Discuss a NASTRAN Finite Element Vibrations Model of the Bell ACAP Helicopter Airframe. NASA CR-181774, May 1989.

19. Dompka, R. V.; Hashish, E.; and Smith, M. R.: Ground Vibration Test Comparisons of a NASTRAN Finite Element Model of the Bell ACAP Helicopter Airframe. NASA CR-181775, May 1989.

20. Gabel, R.; Lang, P. F.; Smith, L. A.; and Reed, D. A.: Plan, Formulate, Discuss and Correlate a
NASTRAN Finite Element Vibrations Model of the Boeing Model 360 Helicopter Airframe. NASA CR-181787, April 1989.

21. Reed, D. A.; and Gabel, R.: Ground Shake Test of the Boeing Model 360 Helicopter Airframe. NASA CR-181766, March 1989.

22. Stebbins, R. F.; and Twomey, W, J.: Plan, Formulate, and Discuss a NASTRAN Finite Element Model of the Sikorsky ACAP Helicopter Airframe. NASA CR-182059, June 1990.

23. Hashemi-Kia, M.; Kilroy, K.; and Parker, G.: Development and Applications of a Multi-Level Strain Energy Method for Detecting Finite Element Modeling Errors. NASA CR-187447, October 1990.

24. Dompka, R. V.: Investigation of Difficult Component Effects on Finite Element Model Vibration Prediction for the Bell AH-1G Helicopter. Volume I - Ground Vibration Test Results. Volume II - Correlation Results. NASA CR-181916, October 1989.

25. Dompka, R. V.: Investigation of Difficult Component Effects on Finite Element Model Vibration Prediction for the Bell ACAP Helicopter. NASA CR-187493, February 1991.

26. Dompka, R. V.; and Cronkhite, J. D.: Summary of AH-IG Flight Vibration Data for Validation of Coupled Rotor-Fuselage Analyses. NASA CR-178160, November 1986.

27. Cronkhite, J. D.; Dompka, R. V.; Rogers, J. P.; Corrigan, J. C.; Perry, K. S.; and Sadler, S. G.: Coupled Rotor/Fuselage Dynamic Analysis of the AH-1G Helicopter and Correlation with Flight Vibrations Data. NASA CR-181723, January 1989.

28. DiTaranto, R. A.; and Sankewitsch, V.: Calculation of Flight Vibration Levels of the AH-1G Helicopter and Correlation with Existing Flight Vibration Measurements. NASA CR. 181923, November 1989.

29. Sangha, K.; and Shamie, J.: Correlation of AHIG Airframe Flight Vibration Data with a Coupled Rotor-Fuselage Analysis. NASA CR181974, August 1990.

30. Sopher, R.; and Twomey, W. J.: Calculation of Flight Vibration Levels of the AH-1G Helicopter and Correlation with Existing Flight Vibration Measurements. NASA CR-182031, April 1990. 
$\vdots$
$\vdots$
$\vdots$
$\vdots$
$\vdots$ 
Public reporting burden for this collection of information is estimated to average 1 hour per response, including the time for reviewing instructions, searching existing data sources gathering and maintaining the data needed, and completing and reviewing the collection of information. Send comments regarding this burden estimate or any other aspert of this Oavis Mighway, Suite 1204. Arlington, VA 22202-4302, and to the Office of Management and Budget, Paperwork Reduction Project (0704-01B8). Washington, DC 20503.

\begin{tabular}{|l|l|l} 
1. AGENCY USE ONLY (Leave blank) & $\begin{array}{l}\text { 2. REPORT DATE } \\
\text { April 1992 }\end{array}$ & $\begin{array}{c}\text { 3. REPORT TYPE AND DATES COVERED } \\
\text { Technical Memorandum }\end{array}$ \\
\hline
\end{tabular}

4. TITLE AND SUBTITLE

The NASA/Industry Design Analysis Methods for

Vibrations (DAMVIBS) Program - A Government Overview

6. AUTHOR(S)

Raymond G. Kvaternik

7. PERFORMING ORGANIZATION NAME(S) AND ADDRESS(ES)

NASA Langley Research Center

Hampton, VA $23665-5225$

9. SPONSORING/MONITORING AGENCY NAME(S) AND ADDRESS(ES)

National Aeronautics and Space Administration

Washington, DC 20546-0001
5. FUNDING NUMBERS

WU 505-63-36-01

11. SUPPLEMENTARY NOTES

Presented at the AIAA/ASME/ASCE/AHS/ASC 33rd Structures, Structural Dynamics, and Materials Conference, Dallas, Texas, April 13-15, 1992.

12a. DISTRIBUTION/AVAILABILITY STATEMENT 12b. DISTRIBUTION CODE

Unclassified - Unlimited

Subject Category 39

13. ABSTRACT (Maximum 200 words)

NASA-Langley, under the Design Analysis Methods for Vibrations (DAMVIBS) Program, set out in 1984 to establish the technology base needed by the rotorcraft industry for developing an advanced finite-element-based dynamics design analysis capability for vibrations. Considerable work has been done by the industry participants in the program since that time. Because the DAMVIBS Program is being phased out, a government/industry assessment of the program has been made to identify those accomplishments and contributions which may be ascribed to the program. The purpose of this paper is to provide an overview of the program and its accomplishments and contributions from the perspective of the government sponsoring organization.

Airframe finite element modeling; rotorcraft airframe vibrations; coupled rotor-airframe vibrations; airframe structural optimization

15. NUMBER OF PAGES

11

16. PRICE CODE

$\mathrm{AO} 3$

\begin{tabular}{|c|c|c|c|}
\hline $\begin{array}{l}\text { 17. SECURITY CLASSIFICATION } \\
\text { OF REPORT } \\
\text { Unclassified }\end{array}$ & $\begin{array}{l}\text { 18. SECURITY CLASSIFICATION } \\
\text { OF THIS PAGE } \\
\text { Unclassified }\end{array}$ & $\begin{array}{l}\text { 19. SECURITY CLASSIFICATION } \\
\text { OF ABSTRACT }\end{array}$ & 20. LIMITATION OF ABSTRACT \\
\hline
\end{tabular}

